\title{
Membrane guanylyl cyclase complexes shape the photoresponses of retinal rods and cones
}

\author{
Xiao-Hong Wen ${ }^{1}{ }^{*}$, Alexander M Dizhoor ${ }^{2}$ and Clint L Makino ${ }^{1}$ \\ ' Department of Ophthalmology, Massachusetts Eye and Ear Infirmary and Harvard Medical School, Boston, MA, USA \\ ${ }^{2}$ Department of Basic Sciences Research and Pennsylvania College of Optometry, Salus University, Elkins Park, PA, USA
}

\section{Edited by:}

Wolfgang Baehr, University of Utah, USA

\section{Reviewed by:}

Daniele Bottai, University of Milan, Italy

Trevor Lamb, Australian National University, Australia

\section{*Correspondence:}

Xiao-Hong Wen, Department of Ophthalmology, Massachusetts Eye and Ear Infirmary and Harvard Medical School, Boston, MA 02114, USA e-mail:wenx@meei.harvard.edu
In vertebrate rods and cones, photon capture by rhodopsin leads to the destruction of cyclic GMP (cGMP) and the subsequent closure of cyclic nucleotide gated ion channels in the outer segment plasma membrane. Replenishment of cGMP and reopening of the channels limit the growth of the photon response and are requisite for its recovery. In different vertebrate retinas, there may be as many as four types of membrane guanylyl cyclases (GCs) for cGMP synthesis. Ten neuronal $\mathrm{Ca}^{2+}$ sensor proteins could potentially modulate their activities. The mouse is proving to be an effective model for characterizing the roles of individual components because its relative simplicity can be reduced further by genetic engineering. There are two types of GC activating proteins (GCAPs) and two types of GCs in mouse rods, whereas cones express one type of GCAP and one type of GC. Mutant mouse rods and cones bereft of both GCAPs have large, long lasting photon responses. Thus, GCAPs normally mediate negative feedback tied to the light-induced decline in intracellular $\mathrm{Ca}^{2+}$ that accelerates $\mathrm{GC}$ activity to curtail the growth and duration of the photon response. Rods from other mutant mice that express a single GCAP type reveal how the two GCAPs normally work together as a team. Because of its lower $\mathrm{Ca}^{2+}$ affinity, GCAP1 is the first responder that senses the initial decrease in $\mathrm{Ca}^{2+}$ following photon absorption and acts to limit response amplitude. GCAP2, with a higher $\mathrm{Ca}^{2+}$ affinity, is recruited later during the course of the photon response as $\mathrm{Ca}^{2+}$ levels continue to decline further. The main role of GCAP2 is to provide for a timely response recovery and it is particularly important after exposure to very bright light. The multiplicity of GC isozymes and GCAP homologs in the retinas of other vertebrates confers greater flexibility in shaping the photon responses in order to tune visual sensitivity, dynamic range and frequency response.

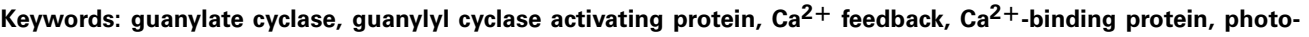
transduction, rod and cone photoreceptors, knockout mouse, neuronal calcium sensors

\section{INTRODUCTION}

Unlike most neurons, retinal rods and cones are partially depolarized while at rest (in darkness). Cation channels in the open state permit an influx of $\mathrm{Na}^{+}$and also some $\mathrm{Ca}^{2+}$ that is termed the "dark" current. When rods and cones receive light, photon capture by visual pigment within the outer segment is amplified by the subsequent activation of many transducin (G-protein) molecules, each of which stimulate phosphodiesterase (PDE) enzymatic activity. Cyclic GMP (cGMP) hydrolysis leads to closure of cyclic nucleotide-gated (CNG) channels thereby blocking the dark current. The ensuing hyperpolarization of membrane potential spreads through the photoreceptor to reduce neurotransmitter release at the synaptic terminal. To recover quickly from stimulation by light, cGMP, the second messenger that links photon capture to CNG channel opening, must be restored (for reviews on phototransduction, see Luo et al., 2008; Wensel, 2008; Gross and Wensel, 2011; Korenbrot, 2012).

Membrane guanylyl cyclases (GCs) catalyze the synthesis of cGMP. As opposed to other membrane GCs, those of photoreceptors do not respond to extracellular ligands, but instead are subject to regulation by $\mathrm{Ca}^{2+}$-binding, EF-hand bearing, GC activating protein (GCAP) subunits (reviewed in Sharma and Duda, 2012; Koch and Dell'Orco, 2013; Lim etal., 2014). GCAP suppresses synthesis of cGMP by GC in darkness, when intracellular $\mathrm{Ca}^{2+}$ is relatively high. After light closes the CNG channels and blocks $\mathrm{Ca}^{2+}$ influx, continued extrusion by $\mathrm{Na}^{+} / \mathrm{K}^{+}$, $\mathrm{Ca}^{2+}$ exchangers lowers intracellular $\mathrm{Ca}^{2+} \cdot \mathrm{Ca}^{2+}$ dissociates from GCAP allowing it to bind $\mathrm{Mg}^{2+}$ instead, whereupon it stimulates GC activity.

Negative feedback onto cGMP synthesis provided by a $\mathrm{Ca}^{2+}$ sensing GCAP is likely to have already been in place in very ancient ciliary photoreceptors (reviewed in Lamb, 2013). Two rounds of whole-genome duplications predating the origin of vertebrates could have generated multiple isoforms. A third genome duplication in fish could explain why they have at least four GCs and eight GCAPs (Imanishi et al., 2004), although it is not clear whether all are expressed in photoreceptors (Figure 1). The existence of multiple isoforms of GC and GCAP provided a substrate for natural selection to optimize the photon response for particular visual ecologies. Where an overly complex system 
of GCs and GCAPs was not needed, components were eventually lost. For example in mouse, three frame deletions degraded the GUCA1C gene for GCAP3 into a pseudogene (Imanishi etal., 2002). But multiple GCs and GCAPs were retained in some species and were possibly even supplemented with GC inhibitory protein (GCIP; Figure 1), that inhibits GC at high $\mathrm{Ca}^{2+}$ but does not stimulate it at low $\mathrm{Ca}^{2+}$ (Li et al., 1998), and unrelated S100 proteins that stimulate $\mathrm{GCl}$ at high $\mathrm{Ca}^{2+}$ (reviewed by Sharma et al., 2014), to tune GC synthesis in order to meet more challenging demands on vision. Over 400 million years of evolution, GCAP1 and GCAP2 genes are ubiquitously preserved in mammals in a tail-to-tail array (Surguchov et al., 1997). In human, there are two isoforms of GCs, RetGC1, and RetGC2 (Lowe et al., 1995), and two isoforms of GCAPs (GCAP1 and GCAP2) in rods (Dizhoor et al., 1994; Palczewski et al., 1994), while at least some cones express an additional GCAP3 (Haeseleer etal., 1999) and possibly only one type of GC (Karan etal., 2010). Three types of GCs and six types of GCAPs are expressed in zebrafish UV cones (Imanishi et al., 2002, 2004; Rätscho etal., 2009), although it remains to be seen whether all are present in the outer segment (Table 1). GCs and GCAPs have responsibilities in the inner segment (reviewed in Karan et al., 2010) and synapse of photoreceptors (reviewed by Schmitz, 2014), both of which constitute separate $\mathrm{Ca}^{2+}$ compartments. Here, we review the progress that has been made in understanding why so many types of GCs

A

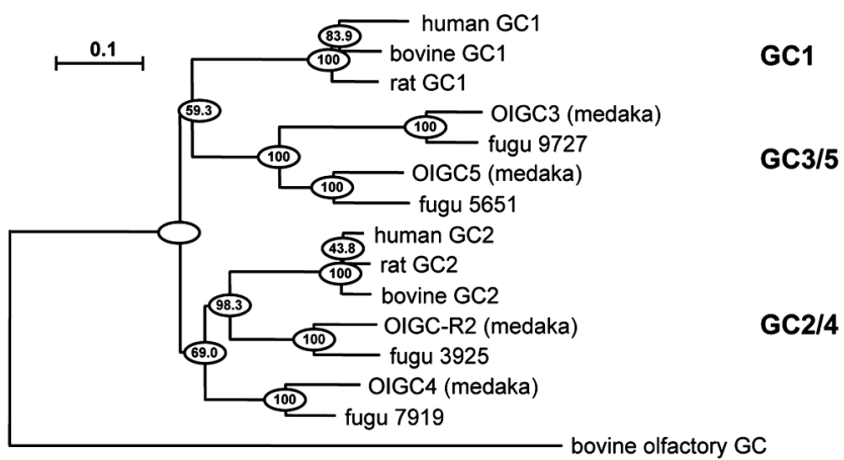

B

GCAP1/5
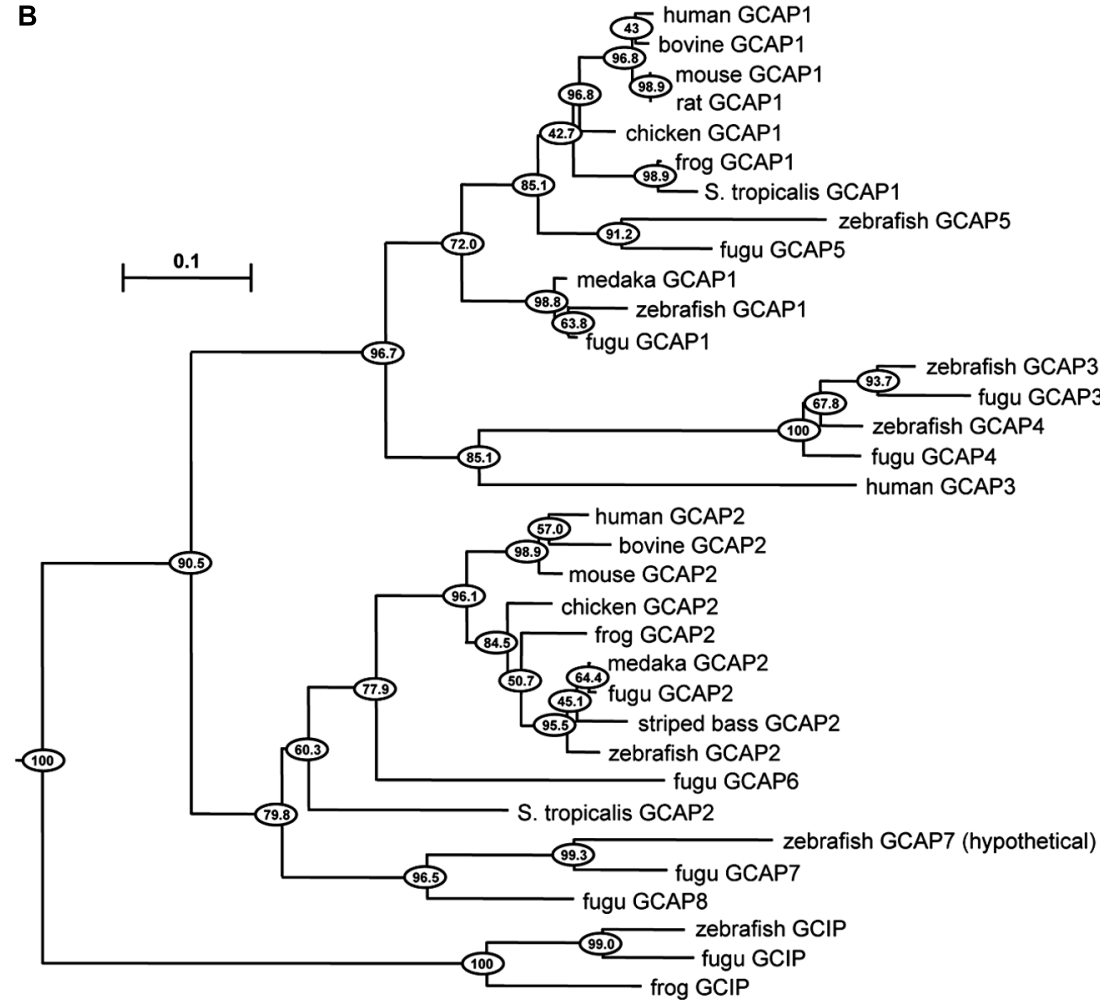

GCAP3/4

GCAP2/6

GCAP7/8

GCIP

FIGURE 1 | Evolutionary relationships of GC and GCAP isoforms in vertebrates. Horizontal branch lengths for GC (A) and GCAP (B) isoforms are proportional to genetic distances. The scale bar indicates 0.1 amino acid substitutions per site. Clustering percentages at the nodes derived from 1000 bootstrap resamplings. Modified from Imanishi et al. (2004) with permission from Springer. 
Table 1 | Distribution of GCs and GCAPs in photoreceptors of mouse, carp, and zebrafish.

\begin{tabular}{|c|c|c|c|c|c|c|c|c|}
\hline & \multicolumn{2}{|c|}{ Mouse } & \multicolumn{2}{|c|}{ Carp } & \multicolumn{4}{|c|}{ Zebrafish } \\
\hline & Rod, $\mu \mathrm{M}$ & Cone & Rod, $\mu \mathbf{M}$ & Cone, $\mu \mathrm{M}$ & Rod & UV cone & B cone & R/G Double cone \\
\hline $\mathrm{GC} 1$ & $3.2-5.8$ & + & 3.9 & - & + & + & - & - \\
\hline $\mathrm{GC} 2$ & $0.8-1.4$ & - & 0.3 & - & + & + & - & - \\
\hline $\mathrm{GC} 3$ & - & - & - & - & - & + & + & + \\
\hline GCAP1 & $+^{*}$ & + & 0.84 & - & + & + & - & - \\
\hline GCAP2 & $+^{*}$ & - & 1.8 & - & + & + & - & - \\
\hline GCAP3 & - & - & - & 33 & - & + & + & + \\
\hline
\end{tabular}

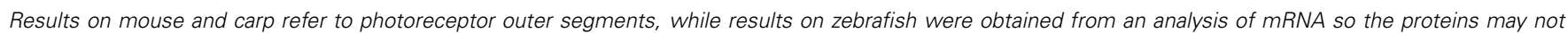

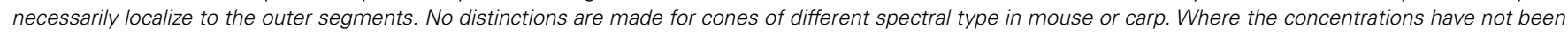

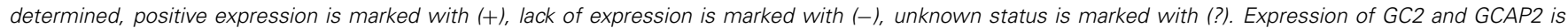

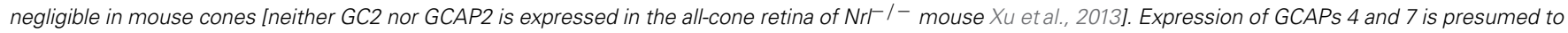

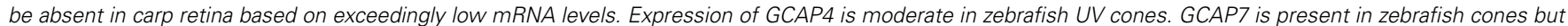

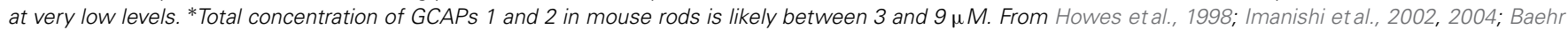
etal., 2007; Rätscho etal., 2009; Takemoto etal., 2009; Peshenko etal., 2011; Scholten and Koch, 2011.

and GCAPs are involved in phototransduction. First, we will consider a relatively simple system that utilizes predominantly two components, GC1 and GCAP1. The impact of genetically deleting the GCAP revealed its role in shaping the response to light. Next, we will describe how this approach was extended to a more complex system that utilizes two additional components. Finally, an extrapolation will be made to other systems in which genetic studies have not yet been carried out or are still in early stages.

\section{A SIMPLE SYSTEM IN MOUSE CONES}

Mouse cones use a simple system for cGMP synthesis with a single type of GC, GC1, coupled almost exclusively to GCAP1 (Table 1). To understand how the $\mathrm{Ca}^{2+}$ feedback onto cGMP synthesis influences the cone photoresponse, it is useful to simplify the system further by genetic engineering. The tacit assumption is that the genetic manipulation "cleanly" removes a targeted protein(s) in an otherwise undisturbed system. Caution is necessary because full verification is impossible and there may be unpredictable consequences. As an illustration, knockout of GC1 in mice interferes with the expression of many cone phototransduction proteins, including transducin, PDE, GCAP1, and arrestin, and the cones eventually degenerate. Surprisingly, small cone ERG responses to light were detected at 1 month of age (Yang et al., 1999), but they soon vanished over the next few weeks as the cones degenerated (Yang et al., 1999; Baehr et al., 2007).

Genetic deletion of GCAPs (GCAPs ${ }^{-/}$) may be a more specific experimental perturbation and cones retain good health. Figure 2A shows that the single photon response of a GCAPs ${ }^{-/-}$ cone rises normally, but continues to do so for twice as long to finally reach a peak after $220 \mathrm{~ms}$ that is 2.7 -fold higher than normal (Sakurai et al., 2011). Integration time, calculated as the integral of the response divided by response amplitude, increases by 2.3 -fold. Loading a WT cone with a $\mathrm{Ca}^{2+}$ buffer to delay the onset of $\mathrm{Ca}^{2+}$ dependent feedback also prolongs its photon response but such treatment does not affect the flash response of a $\mathrm{GCAPs}^{-/-}$cone because GCAP1, the main mediator of the $\mathrm{Ca}^{2+}$-dependent negative feedback onto the phototransduction cascade that dynamically shapes the photon response in mouse cones, is not present.

Since responses to dim steady light summate the responses to individual photons, the large, slow photon responses in GCAPs $^{-/-}$cones should shift the response-intensity relation for steps of light to light intensities $(2.7 \times 2.3)=6.2$ times lower. There is such a shift for very weak responses, however, GCAPs ${ }^{-/-}$ cones are about 20 -fold more sensitive than wild type (WT) cones at the half maximal response level (Figure 2B; Sakurai et al., 2011). The extra shift suggests that the feedback regulation provided by GCAP1 becomes more vigorous when extended exposures to brighter light cause $\mathrm{Ca}^{2+}$ to drop lower than the minimum reached during a single photon response. The steeper $\mathrm{GCAPs}^{-/-}$response-intensity relation for steps of light shows that GCAP1 normally enables cones to operate over a wider range of intensities.

Thus GCAP1 restricts the growth and quickens the recovery of the single photon response in mouse cones, making them less sensitive but improving their temporal resolution. GCAP1 also extends the operating range of cones by preventing saturation when cones are exposed to bright, steady illumination. 


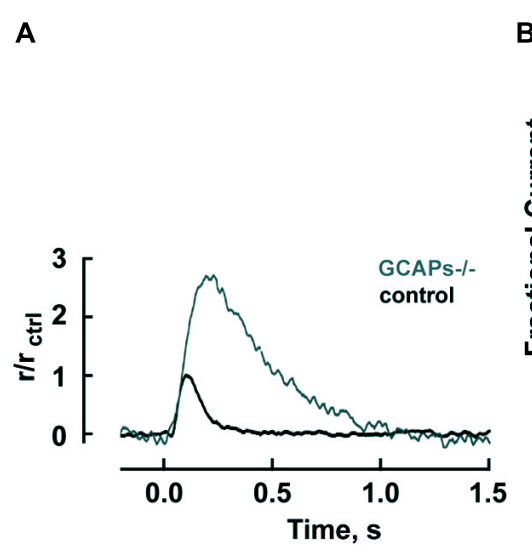

C

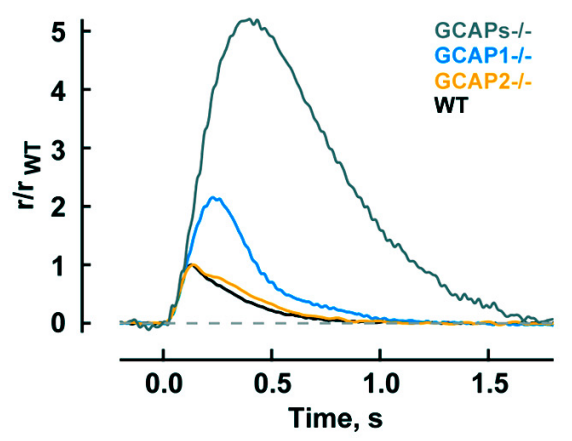

FIGURE 2 | GCAPs shape the photon responses and set the operating ranges of cones and rods. (A) Enlarged, slowed photon response of cones from mice lacking the $\alpha$-subunit of rod transducin, to render rods unresponsive to light, and both GCAPs (Gnat1-/-, GCAPs ${ }^{-/-}$). Control response is from Gnat $1-/-$ cones. Mean responses to flashes given at time zero are normalized by the peak amplitude of the control cone response, $0.01 \mathrm{pA}$. For reasons that are not known, cone response kinetics of this study were slower than those reported by Cao etal. (2014) in Table 2. (B) Shift in the operating range of $\mathrm{GCAPs}^{-/-}$cones to lower intensities. Fractional current is that present $2 \mathrm{~s}$ after light onset. Step intensities are normalized to the mean intensity suppressing half of the dark current for controls, $I_{1 / 2}=94,300 h v \mu \mathrm{m}^{-2} \mathrm{~s}^{-1}$. Continuous lines are

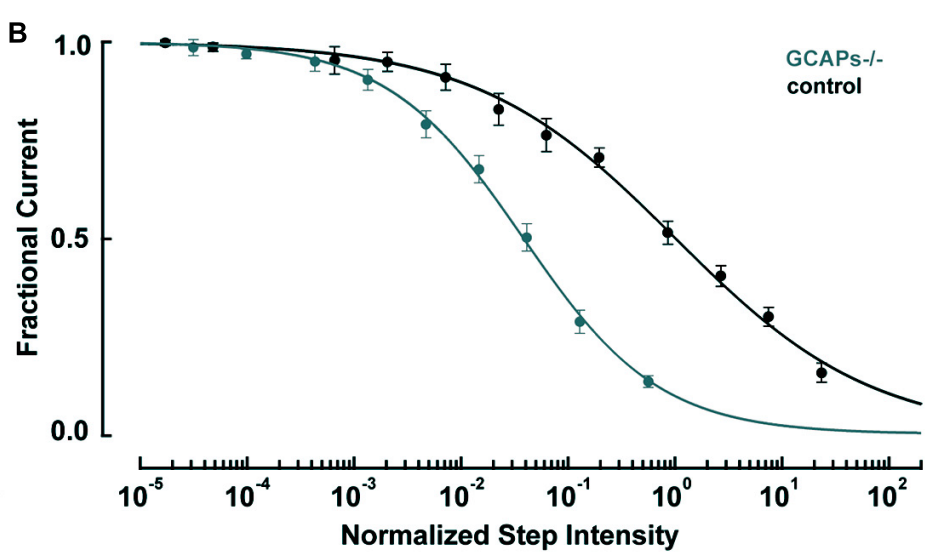

D

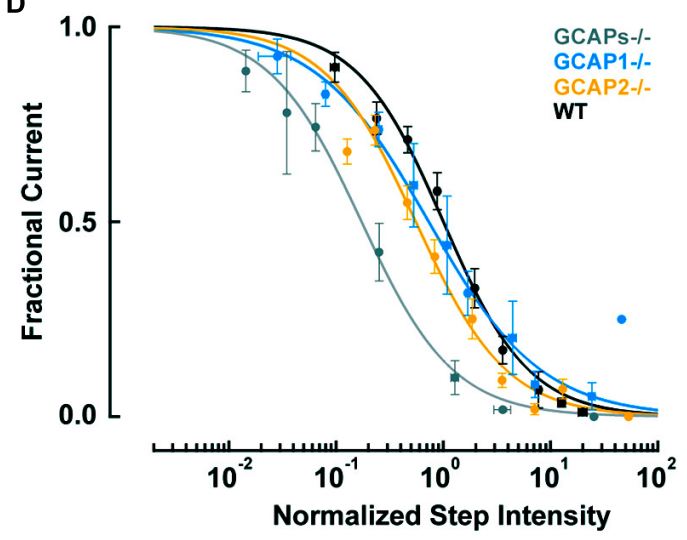

fits with the Hill equation for $\mathrm{GCAPS}^{-/-}$and control cones with Hill coefficients of 0.78 and 0.49 , respectively. (A,B) were adapted from Sakurai etal. (2011) with permission from Society for Neuroscience. (C) Mean single photon responses of WT, GCAP1-/-, GCAP2 - /- , and $\mathrm{GCAPs}^{-1-}$ rods with amplitudes of $0.47,1.02,0.43$, and $2.34 \mathrm{pA}$, respectively, before normalization, includes results from Makino etal. (2008, 2012b). (D) Progressive shift in the rod operating range to lower intensities as one or both GCAPs are knocked out. Fractional current is that remaining after $10 \mathrm{~s}$ of illumination. The mean $\mathrm{I}_{1 / 2}$ for WT rods was

$480 \mathrm{~h} v \mu \mathrm{m}^{-2} \mathrm{~s}^{-1}$. Traces show fits with Hill equation with Hill coefficients of: 1.1, 0.8, 1.0, and 1.0 for WT, GCAP1 $-/-, \mathrm{GCAP}^{-/-}$and $\mathrm{GCAPS}^{-/-}$. (B,D) Error bars show SEM.

\section{GREATER COMPLEXITY IN MOUSE RODS}

In mouse rod outer segments, two GCs coupled to two GCAPs are responsible for cGMP synthesis (Table 1). As with mouse cones, a genetic approach is useful for trying to understand how the system works, but with rods, it is necessary to knock out components individually and in combinations to isolate the physiological function of each component (Yang et al., 1999; Baehr et al., 2007; Makino et al., 2008,2012b). Mutant mice induced to express transgenes for either GCAP1 or GCAP2 on the GCAPs ${ }^{-/-}$background are also informative (Mendez et al., 2001; Howes et al., 2002; Pennesi et al., 2003).

Rods are tasked with counting single photons and are therefore designed to be far more sensitive than cones. Major modifications in rods include slowing of the shutoff and recovery phases of the cascade to grant the photon response time to rise to a large size (reviewed in Luo et al., 2008; Gross and Wensel, 2011; Korenbrot,
2012). In mouse, the rod photon response peaks after $140 \mathrm{~ms}$ at an amplitude of $0.6 \mathrm{pA}$, compared to $80 \mathrm{~ms}$ and $0.012 \mathrm{pA}$ in cones (Table 2). Negative feedback provided by GCAPs is a key factor. The feedback during the single photon response is somewhat more powerful in mouse rods than in mouse cones (Figure 2). In the absence of both GCAPs the rod response rises for three times longer than normal to reach an amplitude that is four times larger (Mendez et al., 2001; Burns et al., 2002). The shift in sensitivity for the $\mathrm{GCAPs}^{-/-}$rod is to flashes 6-8 times dimmer compared to WT rods, greater than the shift of 2-3 times for cones after knockout of both GCAPs (Figure 2A). When GCAP2 alone is missing $\left(\mathrm{GCAP} 2^{-/-}\right)$, the size of the single photon response in rods is normal and the only change is a slightly slower recovery (Makino et al., 2008). Knockout of GCAP1 alone in rods (GCAP1 ${ }^{-/-}$) produces a single photon response roughly twice the normal size (Makino et al., 2012b). So between the two GCAPs, GCAP1 must be the 
Table 2 | Flash response kinetics and relative sensitivity.

\begin{tabular}{|c|c|c|c|c|c|}
\hline & Rod/cone & $a, p A$ & $t_{\mathrm{p}}, \mathrm{ms}$ & $t_{i}, \mathbf{m s}$ & $i_{1 / 2}, h v \mu \mathrm{m}^{-2}$ \\
\hline Monkey & Rod & 0.7 & 190 & 275 & 16 \\
\hline Chipmunk & Rod & 0.5 & 116 & 183 & 153 \\
\hline Monkey & Cone & 0.035 & 48 & 49 & 1744 \\
\hline \multirow[t]{2}{*}{ Salamander } & S cone & 0.3 & 459 & 1209 & 235 \\
\hline & L cone & 0.03 & 155 & 325 & 1409 \\
\hline
\end{tabular}

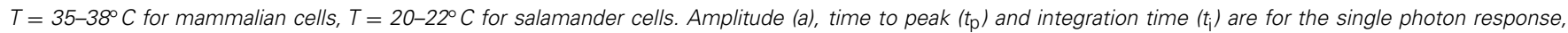

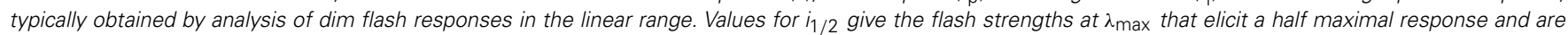

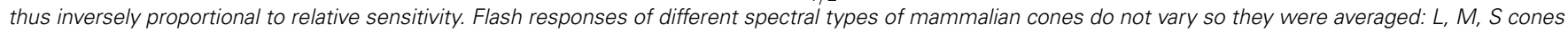

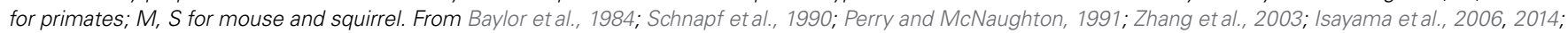

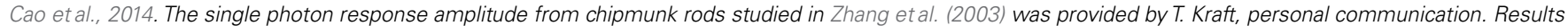

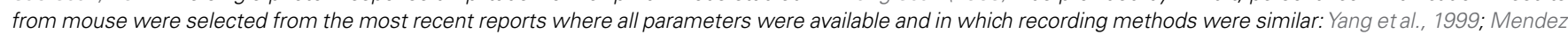
etal., 2001; Makino etal., 2004, 2012a,b; Luo and Yau, 2005; Tsang et al., 2006; Krispel etal., 2007; Woodruff etal., 2007 ; Herrmann etal., 2010.

primary determinant for setting single photon response amplitude. GCAP2 assumes greater importance with stronger flashes (Mendez et al., 2001; Makino et al., 2008). Bright flashes saturate the rod response; the brighter the flash, the longer it takes for the response to emerge from saturation. GCAP2 acts to reduce the saturation time to an extent roughly equivalent to lowering flash strength 3.8-fold (Makino et al., 2008). Loading WT rods with a $\mathrm{Ca}^{2+}$ buffer increases the size of the photon response and alters its kinetics but has no effect on GCAPs ${ }^{-/-}$rods, indicating that as with cones, no other major $\mathrm{Ca}^{2+}$ feedback besides GC/GCAP comes into play during the flash response (Burns et al., 2002).

It might seem that enlarged single photon responses should improve the ability of $\mathrm{GCAPs}^{-/-}$and GCAP $1^{-/-}$rods to count photons. But when GCAPs are not present, there is a 40 -fold greater variance of the dark noise (Burns et al., 2002), which would instead diminish the accuracy of detecting photons. Phototransduction noise stems from two sources: discrete noise due to the thermal activations of rhodopsin (Baylor et al., 1980) and continuous noise due to spontaneous PDE activation (Rieke and Baylor, 1996). GCAPs counteract the cGMP depletion caused by both components (Burns et al., 2002). GCAP1 $1^{-/-}$rods are also noisy, albeit somewhat less so, whereas $\mathrm{GCAP}^{-/-}$rods appear to be normal, indicating that GCAP1 is more important for dampening the noise although GCAP2 likely comes into play when GCAP1 is not present (Figure 3A).

In steady light, given that stimulation of GC activity by GCAPs increases with light intensity as $\mathrm{Ca}^{2+}$ is driven down to lower and lower levels, one might expect GCAPs to extend the operating range of rods by keeping them out of saturation, just as GCAP1 does in cones (Figure 2B). But that does not happen; the relation between fractional current and light intensity does not fall more gradually in WT rods compared to GCAPs $^{-/}-$rods (Figure 2D). One explanation might be that something happens at higher light intensities, such as the summation of long lasting, aberrant photon responses (see below), which undermines the efforts of GCAPs in their attempt to help rods evade saturation. Interestingly, knockout of GCAP1-/- does extend the operating range of rods, perhaps compensatory overexpression of GCAP2 boosts the maximal GC activity and the stimulation of GC activity is concentrated at higher intensities (Makino et al., 2012b).

Mammalian rods possess an odd characteristic: about once per several hundred events, rods generate an aberrant single photon response that climbs to an amplitude nearly twofold larger than normal and then remains at that amplitude for an average of 3-6 s, before recovering. In individual trials, the duration is unpredictable and some aberrant responses last for tens of seconds (Baylor et al., 1984; Chen et al., 1995; Kraft and Schnapf, 1998). Apparently, rhodopsin excitations are not always shut off properly by phosphorylation and arrestin binding (Chen et al., 1995, 1999). The aberrant response is enhanced in the absence of GCAP1, to a greater extent than the normal single photon response (Makino et al., 2012b). Even though aberrant responses are relatively rare, they have a significant physiological impact, because they produce a "tail" that delays the recovery after bright flashes. Tails are especially prominent when GCAP1 is missing (Figure 3B).

The basis for the different roles of GCAP1 and GCAP2 lies in their $\mathrm{Ca}^{2+}$ sensitivities. GCAP1 has a lower affinity for $\mathrm{Ca}^{2+}$ than GCAP2 (Figure 4A). The $\mathrm{K}_{1 / 2}$ for $\mathrm{Ca}^{2+}$ of GCAP1 in the mouse rod is $130-140 \mathrm{nM}$, while that of GCAP2 is $50-60 \mathrm{nM}$ (Makino et al., 2008; Peshenko et al., 2011). Levels of free $\mathrm{Ca}^{2+}$ inside a mouse rod range from $250 \mathrm{nM}$ in darkness to $23 \mathrm{nM}$ in saturating light (Table 3). So during the initial fall in $\mathrm{Ca}^{2+}$ incurred during the photon response, many more GCAP1 molecules release their $\mathrm{Ca}^{2+}$ than GCAP2. The majority of GCAP2 molecules only release their bound $\mathrm{Ca}^{2+}$ when intracellular $\mathrm{Ca}^{2+}$ plummets, during the saturating response to very bright light. A model illustrating the actions of GCAP1 and GCAP2 is shown in Figure 4B. A similar "relay" model was proposed earlier (Koch and Dell'Orco, 2013) but we here prefer the term "recruitment" model to avoid 
A

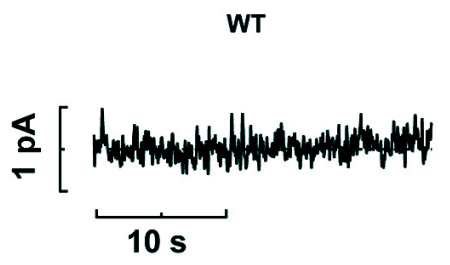

WT

B
GCAP1-/-

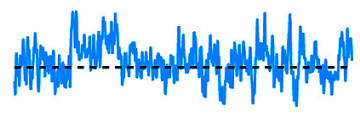

GCAPs-I-

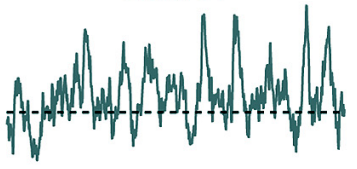

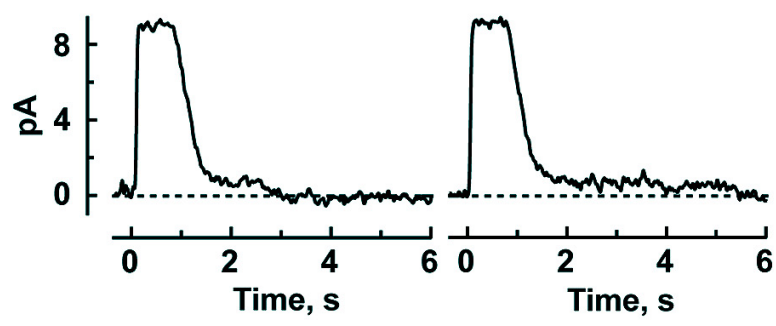

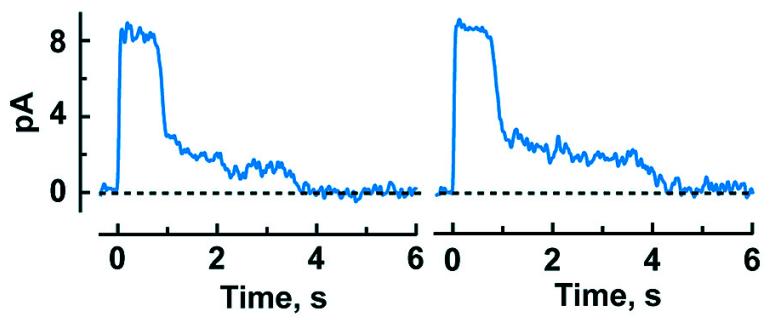

FIGURE 3 | GCAP1 reduces the cGMP fluctuations underlying the dark noise and response tails after exposure to bright light in rods.

(A) Progressive increase in dark noise after GCAP1 and GCAPs knockout, respectively. (B) More prominent photocurrent tails that prolong the recovery after bright light in GCAP1-/- rods. The staircased recovery reflects the stochastic shutoff of aberrant single photon responses generated during the light exposure. Traces are from single trials, where a bright flash was turned on at time zero. Reproduced from Makino etal. (2012b). conveying inadvertently the impression that GCAP2 stimulation substitutes for GCAP1 stimulation at low $\mathrm{Ca}^{2+}$. "Recruitment" emphasizes that GCAP2 adds to stimulation of GC by GCAP1.

The timing of $\mathrm{Ca}^{2+}$ feedback onto GC activity during the photon response is shown in Figure 5A. GC activity ascends at the same rate as the electrical response with a $\sim 40 \mathrm{~ms}$ delay, then declines sharply and falls briefly to a level less than the dark value. GCAP1's lower affinity to $\mathrm{Ca}^{2+}$ makes it the logical "first responder" to the initial decrease in $\mathrm{Ca}^{2+}$ (Figure 4). Although it could have been the case that GCAP2 responds later because it has a slower release of $\mathrm{Ca}^{2+}$ than GCAP1 after a sudden drop in intracellular $\mathrm{Ca}^{2+}$, it will be argued below that both GCAPs are rapid $\mathrm{Ca}^{2+}$ sensors. Figure 5B shows the rising phases of the photon responses of mouse rods lacking GCAP1, GCAP2, or both. The GCAPs ${ }^{-/-}$response is the first to diverge at $\sim 80 \mathrm{~ms}$ after the flash, while the GCAP2 ${ }^{-/-}$response is the last to diverge. Based on this pattern, it may be inferred that GCAP1 senses the fall in $\mathrm{Ca}^{2+}$ and begins to stimulate GC by $80 \mathrm{~ms}$ post-flash. GCAP1-/- rods are highly variable in their response waveforms apparently because they upregulate GCAP2 expression and the degree of compensation differs from rod to rod. Rods with the least compensation show response divergence from the WT response nearly as early as the GCAPs ${ }^{-/-}$response. Accordingly, GCAP2 must respond rapidly to the initial fall in $\mathrm{Ca}^{2+}$. At normal expression levels, the paltry number of GCAP2 molecules responding to the initial fall in $\mathrm{Ca}^{2+}$ is unable to make its presence felt. But the mutant rods show that given enough GCAP2, its feedback onto GC does restrain the early rising phase of the response.

As one might expect, knockout of both GCs in rods eliminates the dark current, sabotaging their capacity for phototransduction (Baehr etal., 2007). Deleting GC2 alone seems to have little effect on the dark current or on flash response kinetics and sensitivity in recordings from individual mouse rods (Baehr et al., 2007). In contrast, GC1 deletion compromises the expression of both GCAPs revealing differences between the duties of the two GCs not directly related to phototransduction in the outer segment. There is an increase in flash sensitivity and a delayed time to peak of the photon response (Yang etal., 1999; Baehr etal., 2007), as predicted from the reduced levels of GCAPs (Mendez et al., 2001). Paradoxically, elimination of GC1 also accelerated the rod response recovery (Yang et al., 1999).

In summary, the functional significance to phototransduction of expressing two types of GCs in rods is not yet clear. For GCAPs, there is a division of labor. GCAP1 helps to achieve the proper balance of keeping noise to a minimum while restricting photon response size to optimize the range of flash strengths and light intensities over which the rod operates. Contrary to the situation in cones, the shutoffs of photoexcited visual pigment and activated transducin are slow in rods to allow the photon response to grow. The slow shutoffs pose a problem with bright flashes because the time that the rod stays in saturation gets prolonged. GCAP2 addresses that problem by boosting GC activity to bring the rod out of saturation sooner.

\section{TUNING $\mathrm{Ca}^{2+}$ FEEDBACK WITH ADDITIONAL GCs AND GCAPS BETWEEN DIFFERENT ANIMAL SPECIES}

While it is generally true that the photon response of rods is larger and slower than that of cones, the response can vary across rods and across cones of different species. The preceding sections described how $\mathrm{Ca}^{2+}$ feedback onto cGMP synthesis reduces the size of the single photon response and quickens its kinetics in mouse rods and cones. The extent to which that occurs is dependent upon the selective expressions of $\mathrm{GC}(\mathrm{s})$ and $\operatorname{GCAP}(\mathrm{s})$. Therefore, variation that exists in the sensitivity and flash response kinetics of rods and cones from 
A

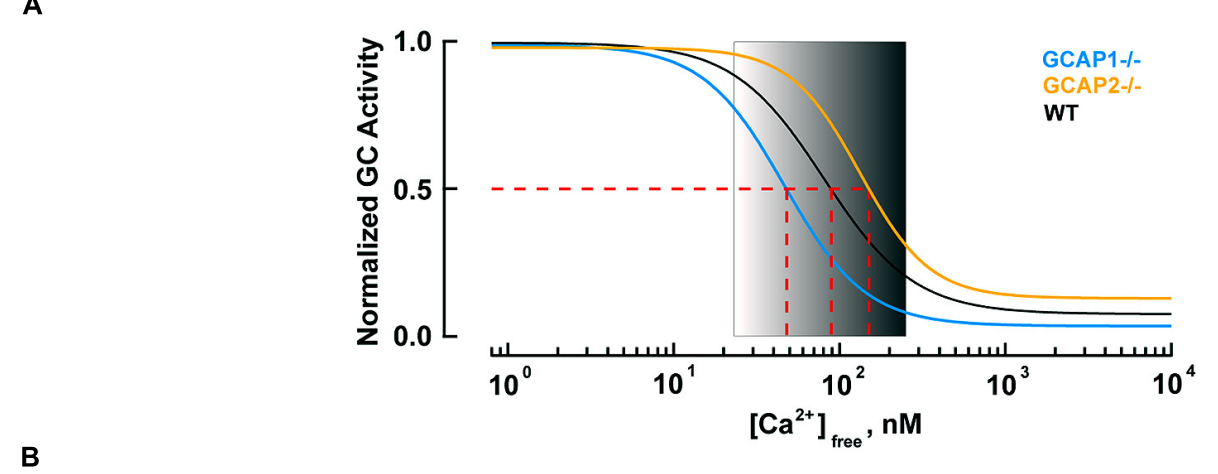

B

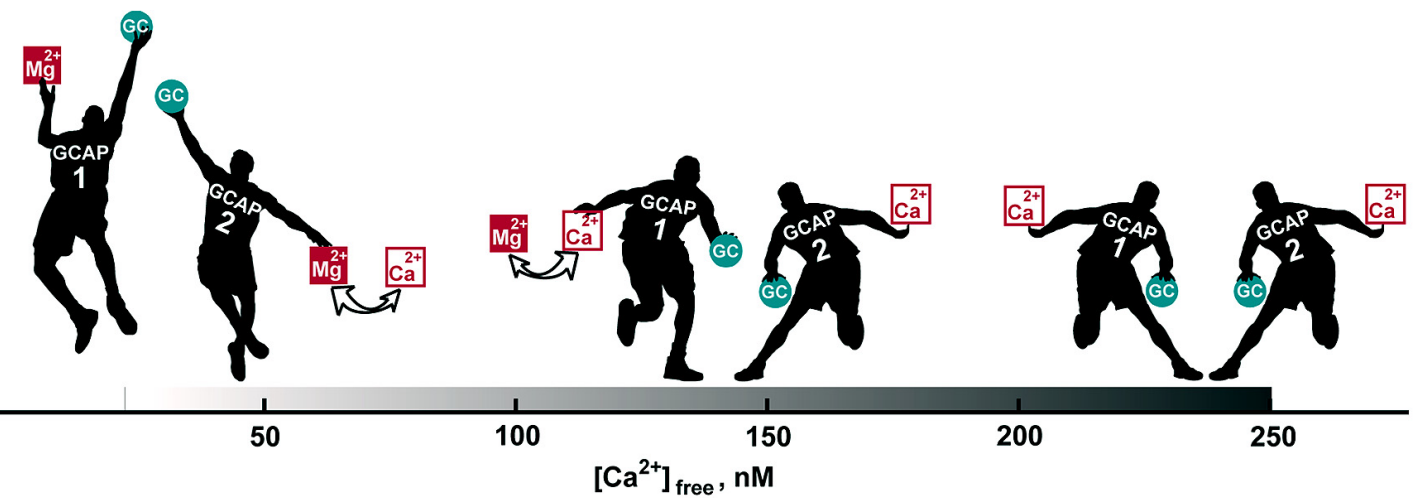

FIGURE $4 \mid \mathrm{Ca}^{2+}$-dependent regulation of GC activity in mouse rods. (A) $\mathrm{Ca}^{2+}$ dependence of GC activity for each GCAP isoform and for the mixture in mouse rods. $G C$ activities are normalized to their respective maxima and follow the Hill equation: $A=\left(A_{\max }-A_{\min }\right) /\left(1+\left(\left[\mathrm{Ca}^{2+}\right] /\right.\right.$ $\left.\left.\mathrm{K}_{1 / 2}\right)^{\mathrm{nH}}\right)+A_{\text {min }}$ with $\mathrm{nH}$ values of $1.8,1.6$, and 2.1 for WT, GCAP1 $1-$ and GCAP2 $2^{-1-}$, respectively. The physiological range of internal free $\mathrm{Ca}^{2+}$ is $23 \mathrm{nM}$ in the light to $250 \mathrm{nM}$ in the dark, as demarcated by the gradient background. Modified from Makino etal. (2008, 2012b). (B) Recruitment model. The physiological free $\mathrm{Ca}^{2}+$ concentration range shown by the black progression at the bottom of the figure. In darkness (right), nearly all of the GCAP1 and 2 "players" bind $\mathrm{Ca}^{2+}$ and suppress GC activity (only a single representative player of each type is shown). Soon after illumination, both GCAPs respond to the light-induced $\mathrm{Ca}^{2+}$ concentration decrease. The disparity in $\mathrm{Ca}^{2}+$ affinity causes many more GCAP1 players to release their bound $\mathrm{Ca}^{2+}$ than GCAP2 players. In that sense, GCAP1 is the "first responder". $\mathrm{Mg}^{2+}$ replaces the released $\mathrm{Ca}^{2+}$ on GCAP, prompting it to raise GC activity (Peshenko and Dizhoor, 2004). As intracellular $\mathrm{Ca}^{2}+$ falls further, the rest of the GCAP2 players exchange $\mathrm{Mg}^{2+}$ for bound $\mathrm{Ca}^{2+}$ and they join the GCAP1 players in lifting GC activity. Very few GCAP2s exchange $\mathrm{Ca}^{2+}$ for $\mathrm{Mg}^{2+}$ during the single photon response, but with bright light, all GCAP1 and GCAP2 players get involved (far left). During the recovery of the response to light, cyclic nucleotide gated (CNG) channels reopen to allow $\mathrm{Ca}^{2+}$ back in. GCAP2 players regain their $\mathrm{Ca}^{2+}$ first and begin to restrain GC. Gradually, as intracellular $\mathrm{Ca}^{2+}$ levels return to baseline, GCAP1 players also regain $\mathrm{Ca}^{2+}$ and turn down GC activity.

Table 3 | Dynamics of intracellular free $\mathrm{Ca}^{2+}$ in the outer segments of rods and cones.

\begin{tabular}{|c|c|c|c|c|}
\hline Type & Time constants, ms & {$\left[\mathrm{Ca}^{2+}\right]_{\text {dark }}, \mathrm{nM}$} & {$\left[\mathrm{Ca}^{2+}\right]_{\text {light }}, \mathrm{nM}$} & {$\left[\mathrm{Ca}^{2+}\right]_{\text {dark }} /\left[\mathrm{Ca}^{2+}\right]_{\text {light }}$} \\
\hline Mouse rod & 154 & 250 & 23 & 11 \\
\hline Salamander rod & 260 & $410-670$ & 30 & $14-22$ \\
\hline Salamander cone & 640 & 410 & 5 & 82 \\
\hline
\end{tabular}

Intracellular free $\mathrm{Ca}^{2+}$ declines after sudden closure of CNG channels by bright light as the sum of two exponential functions. The two time constants listed are from measurements of fluorescent $\mathrm{Ca}^{2+}$ indicators. Electrophysiological measurements of $\mathrm{Ca}^{2+}$ exchange are not included because they often do not resolve the second, slower component. $T=37^{\circ} \mathrm{C}$ for mouse rod, and $T=16-23^{\circ} \mathrm{C}$ for lizard and salamander cells. From Woodruff etal., 2002; Gray-Keller and Detwiler, 1994; Lagnado etal., 1992, Sampath etal., 1998, 1999.

other vertebrates is likely to arise at least in part from differences in their cGMP synthetic machinery. This section will present a few examples of the variation between species and lay out three mechanisms by which cGMP production could be altered to tune the photon response: by augmenting the amounts of GC and GCAP expressed, by a change in intracellular $\mathrm{Ca}^{2+}$ dynamics or by a switch in the types of GCs or GCAPs expressed.

In comparison to mouse rods, primate rods have a single photon response that peaks later whereas the response of chipmunk 
A

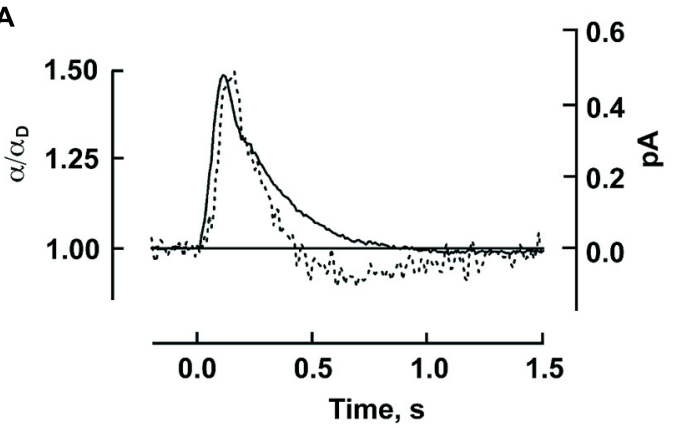

FIGURE 5 | Timeline for GCAP regulated GC activity during the photon response in mouse rods. (A) The calculated time course of GC activity $\alpha$ normalized to the basal value in darkness (broken trace) overlaid on the single photon response (solid trace). The two curves rise with similar slopes to reach their peaks $40 \mathrm{~ms}$ apart. Thereafter, GC activity declines sharply. Reproduced from Burns etal. (2002) with permission from Elsevier. (B) Divergent rising phases of the photon responses of WT rods and rods lacking either or both

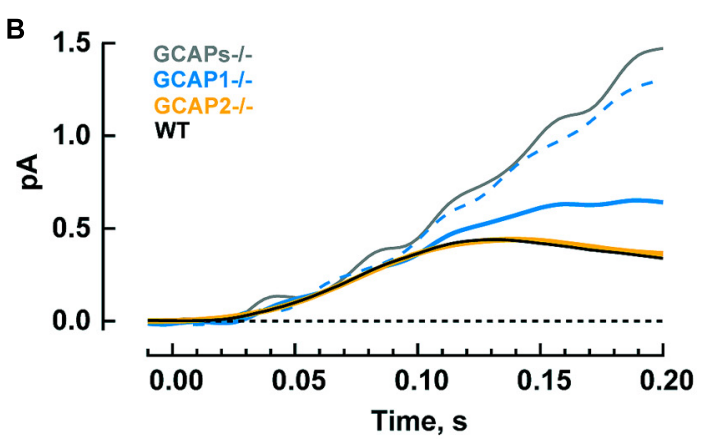

GCAPs. The GCAPs ${ }^{-1}$ - response separates from the WT response at 70-80 ms after the flash. Separation of the larger response of those GCAP1-/ - rods presumed to have little GCAP2 overexpression (dashed blue trace) is next, at $90-100 \mathrm{~ms}$, followed by the smaller response of those GCAP1 1 / - rods presumed to have the most GCAP2 overexpression (solid blue trace) at 100-110 ms. The response of GCAP2 $2^{-/-}$rods overlays the WT until well after the peak. Includes results from Makino et al. (2008, 2012b). rods peaks and recovers earlier (Table 2 ). In general, the single photon response of cones is far smaller and peaks much sooner than the response of rods in the same animal. Across species, ground squirrel cones generate smaller, faster photon responses than mouse cones (Figure 6; Table 2). At present, primate cones are something of an enigma. Their single photon response kinetics are faster than those of mouse yet the single photon response is larger and relative sensitivity is greater. In initial studies on isolated primate retina, cone flash responses exhibited a prominent and reproducible undershoot to the recovery (Baylor et al., 1987; Schnapf et al., 1987; Schnapf et al., 1990). Under the same conditions, cones of other mammals did not generally have undershoots, with the possible exception of chipmunk cones (Zhang et al., 2003). However, in a later study on primate cones, undershoots were absent or only seen occasionally (Figure 6) and kinetics inferred for cones in the intact human eye lack the undershoot (van Hateren and Lamb, 2006). Although flash response kinetics are invariant across cone spectral type in mammal (e.g., Baylor etal., 1987 and Cao et al., 2014), there are distinct differences across cone type in fish and amphibians where faster time to peak corresponds with reduced sensitivity (Perry and McNaughton, 1991; Miller and Korenbrot, 1993; Isayama et al., 2006, 2014). After a partial bleach of the visual pigment content, flash responses of salamander L cones develop an undershoot but flash responses of S cones do not (cf. Figures 4-6 of Isayama et al., 2006).

It has been proposed that an enhanced expression of GC in cones accounts, in part, for their faster flash response kinetics and their ability to signal over an enormous range of light intensities (Takemoto et al., 2009). Expression of GC is 17 times higher in carp cones than in rods (Table 1 ) and the basal rate of cGMP synthesis in cones is an order of magnitude higher. The differential appears to be lower in salamander to account for a basal rate that is only $\sim 3$-fold higher in their cones compared to their rods (Cornwall and Fain, 1994; Cornwall et al., 1995). But despite the higher basal activity in cones, the fold change in stimulation of GC activity in the light is greater in rods than in cones for both carp and

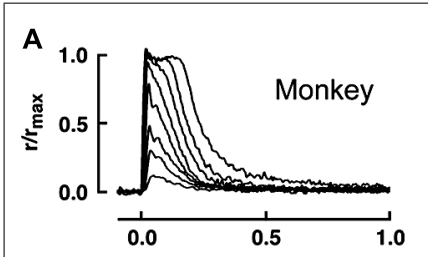

B

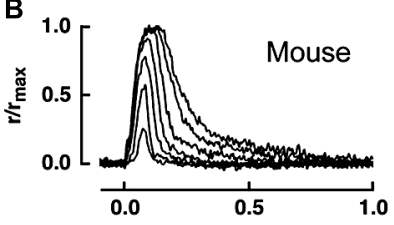

C
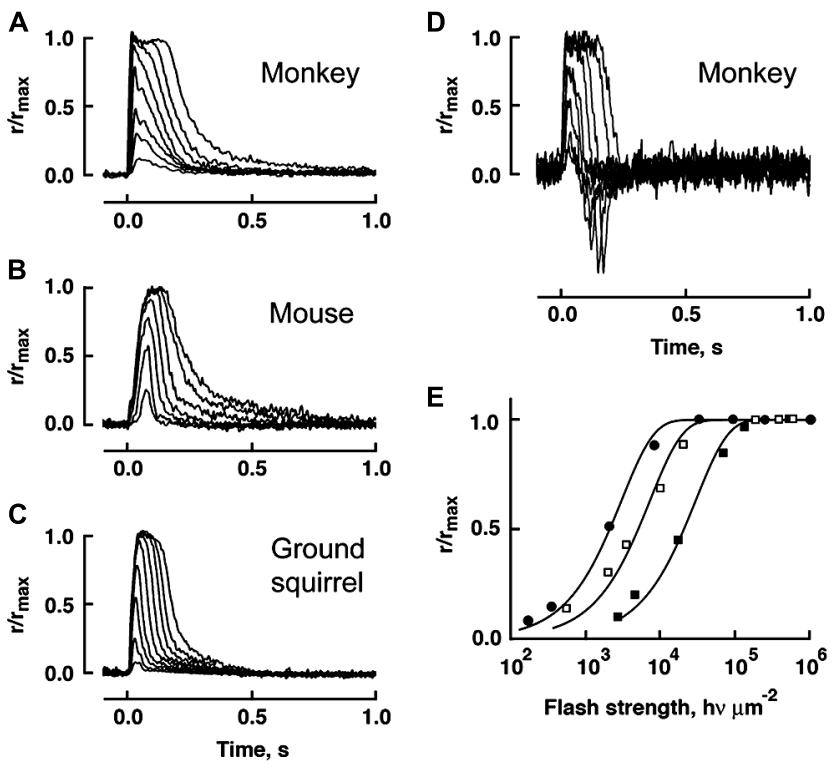

E

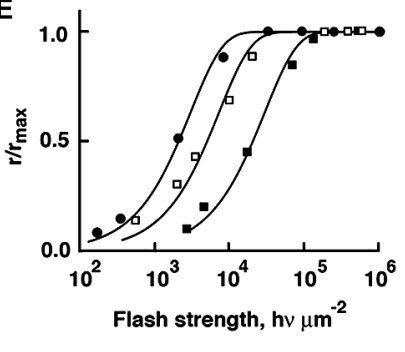

FIGURE 6 | Variation in flash response kinetics and sensitivity across mammalian cones for monkey (A), mouse (B) and squirrel (C). A monkey cone with an undershoot is shown in $\mathbf{D}$. (E) The stimulus-response relations for the cones in $\mathbf{A}-\mathbf{C}$ showing the order of relative flash sensitivity. The monkey cone (circles) is more sensitive than the mouse cone (open squares), which is more sensitive than the squirrel cone (filled squares). Modified with permission from Cao et al. (2014).

salamander. GC will function in the absence of GCAP, so a lower fold change in GC synthesis at low $\mathrm{Ca}^{2+}$ could be achieved by reducing the ratio of GCAP to GC. That turns out not to be the case in carp, indicating that there are quantitative differences in the way that the cGMP synthetic machineries of rods and cones respond to low $\mathrm{Ca}^{2+}$ and/or differences in their $\mathrm{Ca}^{2+}$ dynamics (Takemoto et al., 2009).

Dissimilarities in the operation of the same cGMP synthetic machinery may exist across photoreceptors because of how they 
handle $\mathrm{Ca}^{2+} \cdot \mathrm{Ca}^{2+}$ dynamics in the outer segment depend upon the rates of $\mathrm{Ca}^{2+}$ entry through the $\mathrm{CNG}$ channel and removal by a $\mathrm{Na}^{+} / \mathrm{K}^{+}, \mathrm{Ca}^{2+}$ exchanger, as well as $\mathrm{Ca}^{2+}$ buffering and outer segment surface to volume ratio. In cones, the fraction of circulating current into the outer segment carried by $\mathrm{Ca}^{2+}$ is roughly twice that in rods, due to a greater permeability of the cone CNG channel for $\mathrm{Ca}^{2+}$ (Nakatani and Yau, 1988; Perry and McNaughton, 1991; Ohyama et al., 2000). It is not clear whether the cone exchanger operates at a faster rate than the rod exchanger, but surface to volume is greater in cone outer segments and their time constant for $\mathrm{Ca}^{2+}$ extrusion is faster (Sampath et al., 1999; Paillart et al., 2007). As a result, $\left[\mathrm{Ca}^{2+}\right]$ changes more rapidly and the fold change in $\mathrm{Ca}^{2+}$ levels is bigger in cones than in rods (Table 3). In salamander, a faster rate of $\mathrm{Ca}^{2+}$ extrusion in $\mathrm{L}$ cones than in $\mathrm{S}$ cones may contribute to faster response kinetics of L cones (Perry and McNaughton, 1991). In both salamander rods and cones, the dark level of $\mathrm{Ca}^{2+}$ is higher than in mouse rods, and in salamander cone, the light induced fall in $\mathrm{Ca}^{2+}$ is to $5 \mathrm{nM}$, a lower level than that in mouse rod, $23 \mathrm{nM}$ (Sampath et al., 1999; Woodruff et al., 2002). For feedback on cGMP synthesis to operate over the full range of $\mathrm{Ca}^{2+}$ concentrations, the choice of GCAP(s) expressed will need to be based in part on $\mathrm{Ca}^{2+}$ affinity.

The occurrence of isoforms of GC and GCAP allows for adjustments to be made in their biochemical properties: $\mathrm{K}_{1 / 2}$ for $\mathrm{Ca}^{2+}$, cooperativity for $\mathrm{Ca}^{2+}$ binding, maximal and basal rates of cGMP synthetic activity. Further flexibility stems from having maximal stimulation of GC depend on the pairing of a GC with specific GCAP isoforms. The unstimulated rate of cGMP synthesis by mouse GC1 is nearly 10 -fold less than that of GC2. But stimulation of GC1 activity by GCAP1 and GCAP2 is 28-fold and 13-fold, respectively, whereas for GC2 activity, it is only sixfold and fivefold, respectively (Peshenko et al., 2011). In some cases, the effects of GCAPs on GC are species dependent. Zebrafish GCAP5 will stimulate carp rod GCs severalfold at low $\mathrm{Ca}^{2+}$ concentration but has little effect on carp cone GC (Takemoto et al., 2009). The 6 zebrafish GCAPs differ in the degree to which they will stimulate bovine rod GC activity, ranging from 1.5- to 13-fold (Figure 7), but stimulation of zebrafish GC3 by GCAPs $3-5$ and 7 is more uniform at $\sim 2$-fold (Fries et al., 2013). Carp GCAP1 stimulates carp GC preparations consisting mostly of GC1 to a greater extent than GCAP2 (Takemoto et al., 2009), which is just the opposite of the effect of these zebrafish GCAPs on bovine GC (Scholten and Koch, 2011). These comparisons do not carry physiological significance, nonetheless, it is clear that switching GC and GCAP types is important for setting the basal rate of cGMP synthesis at high $\mathrm{Ca}^{2+}$, the maximal rate at low $\mathrm{Ca}^{2+}$, and the fold activation. In contrast to mouse cones that express GC1 alone, mouse rods add a second GC with a ratio of GC1/GC2 of (4:1) (Peshenko et al., 2011), similar to the (3:1) ratio in bovine rods (Skiba et al., 2013). It should be noted that these recent determinations indicate that the fraction of RetGC2 in mammalian rods is much higher than previously thought (Hwang et al., 2003; Helten et al., 2007).

GCAPs also vary in their $\mathrm{K}_{1 / 2}$ for $\mathrm{Ca}^{2+}$ (Hwang et al., 2003; Peshenko etal., 2011), a property that would appear to be important for optimizing feedback onto cGMP synthesis to the

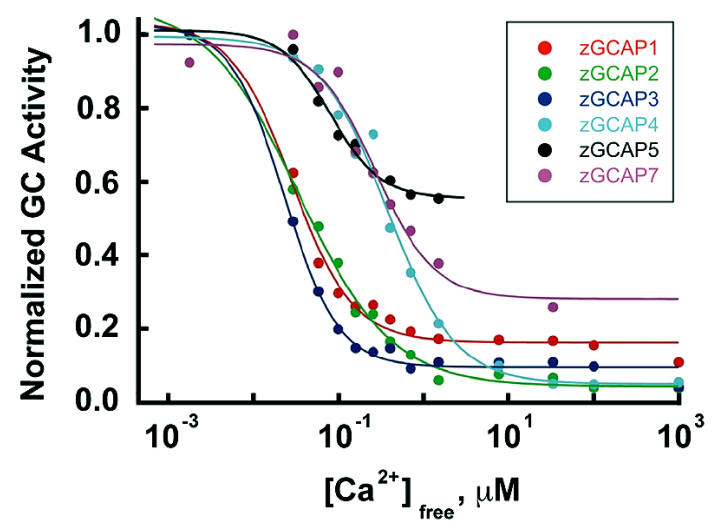

FIGURE $7 \mid \mathrm{Ca}^{2+}$ dependence and extent of GC activation by zebrafish GCAPs. Reconstituted zebrafish GCAPs were assayed in vitro against bovine rod outer segment membranes that were stripped of native GCAPs but contained a mixture of $\mathrm{GC} 1$ and $\mathrm{GC} 2$, with $\mathrm{GC} 1$ predominating. Activity is plotted relative to the maximum rate for each isoform. $K_{1 / 2}$ values are 30 $35,25,520,440$ and $180 \mathrm{nM}$, and the fold activation values are $3,10,6,13$, 1.5, and 2 for zGCAP1-5 and 7, respectively. From Scholten and Koch (2011).

light induced fall in $\mathrm{Ca}^{2+}$. For example, with $\mathrm{K}_{1 / 2}$ values of 130-140 nM and 50-60 nM (Makino et al., 2008; Peshenko et al., 2011), mouse GCAPs 1 and 2 provide little or no incremental activation of GC below $\sim 10 \mathrm{nM}$ (Figure 4A), but intracellular $\left[\mathrm{Ca}^{2+}\right]$ in salamander cones falls to $5 \mathrm{nM}$ upon exposure to bright light. So another GCAP with lower $K_{1 / 2}$ for $\mathrm{Ca}^{2+}$ is needed if cGMP synthetic rate is to increase over the entire $\mathrm{Ca}^{2+}$ range. $\mathrm{K}_{1 / 2}$ values for zebrafish GCAPs 13 cluster at about $30 \mathrm{nM}$ (Figure 7). It remains to be seen whether lower values are possible. Certainly GCAPs, e.g., zGCAPs 4,5 , can have $K_{1 / 2}$ values higher than those of mouse GCAPs (Figure 7), but while such GCAPs may be useful for photoreceptors of lizards and salamanders (Table 3), they cause degenerative retinal disease in mammals (reviewed in Behnen et al., 2010). $\mathrm{Ca}^{2+}$-dependent activation of GC by GCAPs is cooperative (reviewed in Luo etal., 2008; Gross and Wensel, 2011; Korenbrot, 2012) but so far, there is no evidence for differences in their cooperativity (e.g., Peshenko and Dizhoor, 2004) or in the rapidity of their response to low $\mathrm{Ca}^{2+}$ (see above). Given the differences in the composition of their cGMP machineries (Table 1), it may be predicted that the physiological properties of zebrafish cones will vary with spectral type.

The selectivity rules for forming GC complexes are not completely understood. The apparent affinity of mouse GC2 is slightly higher for GCAP2 than for GCAP1 in vitro (Peshenko et al., 2011), yet in living mouse rods, regulation of RetGC2 is heavily dominated by GCAP2 with very little, if any, contribution from GCAP1 (Olshevskaya et al., 2012). Apparently, the selectivity mechanism taking place in vivo is not governed strictly by binding affinity observed in vitro. Thus while the $\mathrm{Ca}^{2+}$ sensitivity of the regulation is determined by the type of GCAP rather than isozyme of the cyclase (Peshenko et al., 2011), the type of GC expressed could shift the GCAP dominance and the $\mathrm{Ca}^{2+}$ sensitivity. 
It may be argued that Nature could have given mouse rods a single GCAP having a $\mathrm{K}_{1 / 2}$ for $\mathrm{Ca}^{2+}$ that matches the value obtained by their mixture of GCAPs 1 and 2. This path was not chosen, perhaps because the flexibility of a mixture of components allowed for adjustments to be made on a shorter evolutionary time scale to accommodate other changes in the phototransduction cascade, as rods evolved as photoreceptors (Lamb, 2013).

On a much shorter time scale, relevant to the lifetime of an individual, the complexity of a mixture of components leaves open many options for plasticity. The absence of GCAP5 transcripts in zebrafish until $15 \mathrm{dpf}$ (Rätscho et al., 2009), even though at least some cones are present by $3 \mathrm{dpf}$ suggests a changeover in the type of GCAP expressed with age. Since each GC has a rank order of preference for GCAPs with which it will form a complex (Takemoto etal., 2009; Peshenko et al., 2011; Scholten and Koch, 2011; Olshevskaya et al., 2012), relative expression levels of each GCAP may be a factor in determining which GC/GCAP complexes predominate. In zebrafish cones, GCAP3 expression exceeds GC3 expression by an order of magnitude, yet there is no change in optomotor behavior upon knockdown of GCAP3 (Fries et al., 2013). Presumably, GCAP3 is replaced with a GCAP having similar properties. However, it is possible that reduced expression of a different GCAP would result in greater incorporation of GCAP3 with a change in visual function. In mice, knockout of GCAP2 has no effect on GCAP1 expression, but knockout of GCAP1 drives an increase in GCAP2 expression with a greater fractional incorporation of GCAP2 into GC complexes that yields a higher maximal GC activity at low $\mathrm{Ca}^{2+}$ (Makino etal., 2012b). It is tempting to speculate that GCAP1 expression may fall under transcriptional control by some conditions. Exposure to bright light reduced $\operatorname{PDE} \alpha$ mRNA levels in mice by twofold (Krishnan etal., 2008) and $\mathrm{PDE} \alpha$ and $\mathrm{PDE} \beta$ protein levels in rat by threefold (Hajkova et al., 2010). In rat, there were no changes in GC1 (GC-E) expression; other cGMP synthetic machinery components were not reported. Then unless another GC activity went down, cGMP levels would have risen. GCAPs are sensitive to the $\left[\mathrm{Mg}^{2+}\right]$, which allows them to maintain their cyclase activating conformation in the light and affects the $\left[\mathrm{Ca}^{2+}\right]$ at which they de-activate GC (Peshenko and Dizhoor, 2004). However, evidence so far indicates that internal $\left[\mathrm{Mg}^{2+}\right]$ does not change in rods or in cones upon exposure to light and remains in the vicinity of $1 \mathrm{mM}$ (Chen etal., 2003). So while the potential exists for changes in the choice of GC or GCAP expressed and in their relative levels of expression during development or in response to environmental conditions, the issue of plasticity is at present, unresolved.

Evolution has favored the occurrence of multiple isoforms of GCAPs that vary in their $\mathrm{Ca}^{2+}$ affinity and GCs with different activities and preferences for the type of GCAP bound. By expressing selected components and regulating their levels of expression, vertebrates "design" the cGMP synthetic machinery in their photoreceptors in order to adjust their physiological responses to light stimuli. The possibility exists for plasticity during development or on a shorter time scale to meet changing visual demands.

\section{ACKNOWLEDGMENTS}

This work was supported by the Howe Laboratory Endowment of the Massachusetts Eye and Ear Infirmary, Research to Prevent Blindness, National Eye Institute EY014104, EY011522. Alexander M. Dizhoor is the Martin and Florence Hafter Chair Professor of Pharmacology. The authors bear sole responsibility for the contents herein. The views expressed do not necessarily convey those of the National Eye Institute.

\section{REFERENCES}

Baehr, W., Karan, S., Maeda, T., Luo, D.-G., Li, S., Bronson, J. D., et al. (2007). The function of guanylate cyclase 1 and guanylate cyclase 2 in rod and cone photoreceptors. J. Biol. Chem. 282, 8837-8847. doi: 10.1074/jbc.M610369200

Baylor, D. A., Matthews, G., and Yau, K.-W. (1980). Two components of electrical dark noise in toad retinal rod outer segments. J. Physiol. 309, 591-621.

Baylor, D. A., Nunn, B. J., and Schnapf, J. L. (1984). The photocurrent, noise and spectral sensitivity of rods of the monkey Macaca fascicularis. J. Physiol. 357, 575-607.

Baylor, D. A., Nunn, B. J., and Schnapf, J. L. (1987). Spectral sensitivity of cones of the monkey Macaca fascicularis. J. Physiol. 390, 145-160.

Behnen, P., Dell'Orco, D., and Koch, K.-W. (2010). Involvement of the calcium sensor GCAP1 in hereditary cone dystrophies. Biol. Chem. 391, 631-637. doi: 10.1515/BC.2010.063

Burns, M. E., Mendez, A., Chen, J., and Baylor, D. A. (2002). Dynamics of cyclic GMP synthesis in retinal rods. Neuron 36, 81-91. doi: 10.1016/S0896-6273(02)00911-X

Cao, L.-H., Luo, D.-G., and Yau, K.-W. (2014). Light responses of primate and other mammalian cones. Proc. Natl. Acad. Sci. U.S.A. 111, 2752-2757. doi: 10.1073/pnas.1400268111

Chen, C., Nakatani, K., and Koutalos, Y. (2003). Free magnesium concentration in salamander photoreceptor outer segments. J. Physiol. 553, 125-135. doi: 10.1113/jphysiol.2003.053280

Chen, C. K., Burns, M. E., Spencer, M., Niemi, G. A., Chen, J., Hurley, J. B., et al. (1999). Abnormal photoresponses and light-induced apoptosis in rods lacking rhodopsin kinase. Proc. Natl. Acad. Sci. U.S.A. 96, 3718-3722. doi: 10.1073/pnas.96.7.3718

Chen, J., Makino, C. L., Peachey, N. S., Baylor, D. A., and Simon, M. I. (1995). Mechanisms of rhodopsin inactivation in vivo as revealed by a $\mathrm{COOH}$-terminal truncation mutant. Science 267, 374-377. doi: 10.1126/science.7824934

Cornwall, M. C., and Fain, G. L. (1994). Bleached pigment activates transduction in isolated rods of the salamander retina. J. Physiol. 480, 261-279.

Cornwall, M. C., Matthews, H. R., Crouch, R. K., and Fain, G. L. (1995). Bleached pigment activates transduction in salamander cones. J. Gen. Physiol. 106, 543-557. doi: 10.1085/jgp.106.3.543

Dizhoor, A. M., Lowe, D. G., Olshevskaya, E. V., Laura, R. P., and Hurley, J. B. (1994). The human photoreceptor membrane guanylyl cyclase, RetGC, is present in outer segments and is regulated by calcium and a soluble activator. Neuron 12 , 1345-1352. doi: 10.1016/0896-6273(94)90449-9

Fries, R., Scholten, A., Säftel, W., and Koch, K.-W. (2013). Zebrafish guanylate cyclase type 3 signaling in cone photoreceptors. PLOS ONE 8:e69656. doi: 10.1371/journal.pone.0069656

Gray-Keller, M. P., and Detwiler, P. B. (1994). The calcium feedback signal in the phototransduction cascade of vertebrate rods. Neuron 13, 849-861. doi: 10.1016/0896-6273(94)90251-8

Gross, A. K., and Wensel, T. G. (2011). "Biochemical cascade of phototransduction," in Adler's Physiology of the Eye, 11th Edn, eds L. A. Levin, S. F. E. Nilsson, J. Ver Hoeve, S. M. Wu, P. L. Kaufman, and A. Alm (Philadelphia: Saunders/Elsevier B.V.), 394-410.

Haeseleer, F., Sokal, I., Li, N., Pettenati, M., Rao, N., Bronson, D., et al. (1999). Molecular characterization of a third member of the guanylyl cyclase-activating protein subfamily. J. Biol. Chem. 274, 6526-6535. doi: 10.1074/jbc.274.10.6526

Hajkova, D., Imanishi, Y., Palamalai, V., Rao, K. C. S., Yuan, C., Sheng, Q., et al. (2010). Proteomic changes in the photoreceptor outer segment upon intense light exposure. J. Proteome Res. 9, 1173-1181. doi: 10.1021/pr900819k

Helten, A., Säftel, W., and Koch, K.-W. (2007). Expression level and activity profile of membrane bound guanylate cyclase type 2 in rod outer segments. J. Neurochem. 103, 1439-1446. doi: 10.1111/j.1471-4159.2007.04923.x 
Herrmann, R., Lobanova, E. S., Hammond, T., Kessler, C., Burns, M. E., Frishman, L. J., et al. (2010). Phosducin regulates transmission at the photoreceptor-to-ONbipolar cell synapse. J. Neurosci. 30, 3239-3253. doi: 10.1523/JNEUROSCI.477509.2010

Howes, K., Bronson, J. D., Dang, Y. L., Li, N., Zhang, K., Ruiz, C., et al. (1998). Gene array and expression of mouse retina guanylate cyclase activating proteins 1 and 2. Invest. Ophthalmol. Vis. Sci. 39, 867-875.

Howes, K. A., Pennesi, M. E., Sokal, I., Church-Kopish, J., Schmidt, B., Margolis, D., et al. (2002). GCAP1 rescues rod photoreceptor response in GCAP1/GCAP2 knockout mice. EMBO J. 21, 1545-1554. doi: 10.1093/emboj/21.7.1545

Hwang, J.-Y., Lange, C., Helten, A., Höppner-Heitmann, D., Duda, T., Sharma, R. K., et al. (2003). Regulatory modes of rod outer segment membrane guanylate cyclase differ in catalytic efficiency and $\mathrm{Ca}^{2+}$-sensitivity. Eur. J. Biochem. 270, 3814-3821. doi: 10.1046/j.1432-1033.2003.03770.x

Imanishi, Y., Li, N., Sokal, I., Sowa, M. E., Lichtarge, O., Wensel, T. G., etal. (2002). Characterization of retinal guanylate cyclase-activating protein 3 (GCAP3) from zebrafish to man. Eur. J. Neurosci. 15, 63-78. doi: 10.1046/j.0953-816x.2001.01835.x

Imanishi, Y., Yang, L., Sokal, I., Filipek, S., Palczewski, K., and Baehr, W. (2004). Diversity of guanylate cyclase-activating proteins (GCAPs) in teleost fish: characterization of three novel GCAPs (GCAP4, GCAP5, GCAP7) from zebrafish (Danio rerio) and prediction of eight GCAPs (GCAP1-8) in pufferfish (Fugu rubripes). J. Mol. Evol. 59, 204-217. doi: 10.1007/s00239-004-2614-y

Isayama, T., Chen, Y., Kono, M., DeGrip, W. J., Ma, J.-X., Crouch, R. K., et al. (2006). Differences in the pharmacological activation of visual opsins. Vis. Neurosci. 23, 899-908. doi: 10.1017/S0952523806230256

Isayama, T., Chen, Y., Kono, M., Fabre, E., Slavsky, M., DeGrip, W. J., et al. (2014). Coexpression of three opsins in cone photoreceptors of the salamander, Ambystoma tigrinum. J. Comp. Neurol. 522, 2249-2265. doi: 10.1002/cne. 23531

Karan, S., Frederick, J. M., and Baehr, W. (2010). Novel functions of photoreceptor guanylate cyclases revealed by targeted deletion. Mol. Cell. Biochem. 334, 141-155. doi: 10.1007/s11010-009-0322-z

Koch, K.-W., and Dell'Orco, D. (2013). A calcium-relay mechanism in vertebrate phototransduction. ACS Chem. Neurosci. 4, 909-917. doi: 10.1021/cn400027z

Korenbrot, J. I. (2012). Speed, sensitivity, and stability of the light response in rod and cone photoreceptors: facts and models. Prog. Retin. Eye Res. 31, 442-466. doi: 10.1016/j.preteyeres.2012.05.002

Kraft, T. W., and Schnapf, J. L. (1998). Aberrant photon responses in rods of the macaque monkey. Vis. Neurosci. 15, 153-159. doi: 10.1017/S0952523898151131

Krishnan, J., Chen, J., Shin, K.-J., Hwang, J.-I., Han, S.-U., Lee, G., et al. (2008). Gene expression profiling of light-induced retinal degeneration in phototransduction gene knockout mice. Exp. Mol. Med. 40, 495-504. doi: 10.3858/emm.2008.40.5.495

Krispel, C. M., Sokolov, M., Chen, Y.-M., Song, H., Herrmann, R., Arshavsky, V. Y., et al. (2007). Phosducin regulates the expression of transducin $\beta \gamma$ subunits in rod photoreceptors and does not contribute to phototransduction adaptation. J. Gen. Physiol. 130, 303-312. doi: 10.1085/jgp.200709812

Lagnado, L., Cervetto, L., and McNaughton, P. A. (1992). Calcium homeostasis in the outer segments of retinal rods from the tiger salamander. J. Physiol. 455, 111-142.

Lamb, T. D. (2013). Evolution of phototransduction, vertebrate photoreceptors and retina. Prog. Retin. Eye Res. 36, 52-119. doi: 10.1016/j.preteyeres.2013.06.001

Li, N., Fariss, R. N., Zhang, K., Otto-Bruc, A., Haeseleer, F., Bronson, D., et al. (1998). Guanylate-cyclase-inhibitory protein is a frog retinal $\mathrm{Ca}^{2+}$-binding protein related to mammalian guanylate-cyclase-activating proteins. Eur. J. Biochem. 252, 591-599. doi: 10.1046/j.1432-1327.1998. 2520591.x

Lim, S., Dizhoor, A. M., and Ames, J. B. (2014). Structural diversity of neuronal calcium sensor proteins and insights for activation of retinal guanylyl cyclase by GCAP1. Front. Mol. Neurosci. 7:19. doi: 10.3389/fnmol.2014.00019

Lowe, D. G., Dizhoor, A. M., Liu, K., Gu, Q., Spencer, M., Laura, R., et al. (1995). Cloning and expression of a second photoreceptor-specific membrane retina guanylyl cyclase (RetGC), RetGC-2. Proc. Natl. Acad. Sci. U.S.A. 92, 5535-5539. doi: $10.1073 /$ pnas.92.12.5535

Luo, D.-G., Xue, T., and Yau, K.-W. (2008). How vision begins: an odyssey. Proc. Natl. Acad. Sci. U.S.A. 105, 9855-9862. doi: 10.1073/pnas.07084 05105
Luo, D.-G., and Yau, K.-W. (2005). Rod sensitivity of neonatal mouse and rat. J. Gen. Physiol. 126, 263-269. doi: 10.1085/jgp.200509342

Makino, C. L., Dodd, R. L., Chen, J., Burns, M. E., Roca, A., Simon, M. I., et al. (2004). Recoverin regulates light-dependent phosphodiesterase activity in retinal rods. J. Gen. Physiol. 123, 729-741. doi: 10.1085/igp.200308994

Makino, C. L., Peshenko, I. V., Wen, X.-H., Olshevskaya, E. V., Barrett, R., and Dizhoor, A. M. (2008). A role for GCAP2 in regulating the photoresponse. Guanylyl cyclase activation and rod electrophysiology in GUCA1B knock-out mice. J. Biol. Chem. 283, 29135-29143. doi: 10.1074/jbc.M8044 45200

Makino, C. L., Wen, X.-H., Michaud, N. A., Covington, H. I., DiBenedetto, E., Hamm, H. E., et al. (2012a). Rhodopsin expression level affects rod outer segment morphology and photoresponse kinetics. PLoS ONE 7:e37832. doi: 10.1371/journal.pone.0037832

Makino, C. L., Wen, X.-H., Olshevskaya, E. V., Peshenko, I. V., Savchenko, A. B., and Dizhoor, A. M. (2012b). Enzymatic relay mechanism stimulates cyclic GMP synthesis in rod photoresponse: biochemical and physiological study in guanylyl cyclase activating protein 1 knockout mice. PLoS ONE 7:e47637. doi: 10.1371/journal.pone.0047637

Mendez, A., Burns, M. E., Sokal, I., Dizhoor, A. M., Baehr, W., Palczewski, K., et al. (2001). Role of guanylate cyclase-activating proteins (GCAPs) in setting the flash sensitivity of rod photoreceptors. Proc. Natl. Acad. Sci. U.S.A. 98, 9948-9953. doi: $10.1073 /$ pnas. 171308998

Miller, J. L., and Korenbrot, J. I. (1993). Phototransduction and adaptation in rods, single cones, and twin cones of the striped bass retina: a comparative study. Vis. Neurosci. 10, 653-667. doi: 10.1017/S0952523800005356

Nakatani, K., and Yau, K.-W. (1988). Calcium and magnesium fluxes across the plasma membrane of the toad rod outer segment. J. Physiol. 395, 695-729.

Ohyama, T., Hackos, D. H., Frings, S., Hagen, V., Kaupp, U. B., and Korenbrot, J. I. (2000). Fraction of the dark current carried by $\mathrm{Ca}^{2+}$ through cGMP-gated ion channels of intact rod and cone photoreceptors. J. Gen. Physiol. 116, 735-754. doi: 10.1085/jgp.116.6.735

Olshevskaya, E. V., Peshenko, I. V., Savchenko, A. B., and Dizhoor, A. M. (2012). Retinal guanylyl cyclase isozyme 1 is the preferential in vivo target for constitutively active GCAP1 mutants causing congenital degeneration of photoreceptors. J. Neurosci. 32, 7208-7217. doi: 10.1523/JNEUROSCI.097612.2012

Paillart, C., Winkfein, R. J., Schnetkamp, P. P. M., and Korenbrot, J. I. (2007). Functional characterization and molecular cloning of the $\mathrm{K}^{+}$-dependent $\mathrm{Na}^{+} / \mathrm{Ca}^{2+}$ exchanger in intact retinal cone photoreceptors. J. Gen. Physiol. 129, 1-16. doi: 10.1085/jgp.200609652

Palczewski, K., Subbaraya, I., Gorczyca, W. A., Helekar, B. S., Ruiz, C. C., Ohguro, H., et al. (1994). Molecular cloning and characterization of retinal photoreceptor guanylyl cyclase-activating protein. Neuron 13, 395-404. doi: 10.1016/0896-6273(94)90355-7

Pennesi, M. E., Howes, K. A., Baehr, W., and Wu, S. M. (2003). Guanylate cyclase-activating protein (GCAP) 1 rescues cone recovery kinetics in GCAP1/GCAP2 knockout mice. Proc. Natl. Acad. Sci. U.S.A. 100, 6783-6788. doi: 10.1073/pnas.1130102100

Perry, R. J., and McNaughton, P. A. (1991). Response properties of cones from the retina of the tiger salamander. J. Physiol. 433, 561-587.

Peshenko, I. V., and Dizhoor, A. M. (2004). Guanylyl cyclase-activating proteins (GCAPs) are $\mathrm{Ca}^{2+} / \mathrm{Mg}^{2+}$ sensors: implications for photoreceptor guanylyl cyclase (RetGC) regulation in mammalian photoreceptors. J. Biol. Chem. 279, 1690316906. doi: 10.1074/jbc.C400065200

Peshenko, I. V., Olshevskaya, E. V., Savchenko, A. B., Karan, S., Palczewski, K., Baehr, W., etal. (2011). Enzymatic properties and regulation of the native isozymes of retinal membrane guanylyl cyclase (RetGC) from mouse photoreceptors. Biochemistry 50, 5590-5600. doi: 10.1021/bi200491b

Rätscho, N., Scholten, A., and Koch, K.-W. (2009). Expression profiles of three novel sensory guanylate cyclases and guanylate cyclase-activating proteins in the zebrafish retina. Biochim. Biophys. Acta 1793, 1110-1114. doi: 10.1016/j.bbamcr.2008.12.021

Rieke, F., and Baylor, D. A. (1996). Molecular origin of continuous dark noise in rod photoreceptors. Biophys. J. 71, 2553-2572. doi: 10.1016/S0006-3495(96)79448-1 Sakurai, K., Chen, J., and Kefalov, V. J. (2011). Role of guanylyl cyclase modulation in mouse cone phototransduction. J. Neurosci. 31, 7991-8000. doi: 10.1523/JNEUROSCI.6650-10.2011 
Sampath, A. P., Matthews, H. R., Cornwall, M. C., Bandarchi, J., and Fain, G. L. (1999). Light-dependent changes in outer segment free- $\mathrm{Ca}^{2+}$ concentration in salamander cone photoreceptors. J. Gen. Physiol. 113, 267-277. doi: 10.1085/jgp.113.2.267

Sampath, A. P., Matthews, H. R., Cornwall, M. C., and Fain, G. L. (1998). Bleached pigment produces a maintained decrease in outer segment $\mathrm{Ca}^{2+}$ in salamander rods. J. Gen. Physiol. 111, 53-64. doi: 10.1085/jgp.111.1.53

Schmitz, F. (2014). Presynaptic $\left[\mathrm{Ca}^{2+}\right]$ and GCAPs: aspects on the structure and function of photoreceptor ribbon synapses. Front. Mol. Neurosci. 7:3. doi: 10.3389/fnmol.2014.00003

Schnapf, J. L., Kraft, T. W., and Baylor, D. A. (1987). Spectral sensitivity of human cone photoreceptors. Nature 325, 439-441. doi: 10.1038/325439a0

Schnapf, J. L., Nunn, B. J., Meister, M., and Baylor, D. A. (1990). Visual transduction in cones of the monkey Macaca fascicularis. J. Physiol. 427, 681-713.

Scholten, A., and Koch, K.-W. (2011). Differential calcium signaling by cone specific guanylate cyclase-activating proteins from the zebrafish retina. PLoS ONE 6:e23117. doi: 10.1371/journal.pone.0023117

Sharma, R. K., and Duda, T. (2012). $\mathrm{Ca}^{2+}$-sensors and ROS-GC: interlocked sensory transduction elements: a review. Front. Mol. Neurosci. 5:42. doi: 10.3389/fnmol.2012.00042

Sharma, R. K., Makino, C. L., Hicks, D., and Duda, T. (2014). ROS-GC interlocked $\mathrm{Ca}^{2+}$-sensor S100B protein signaling in cone photoreceptors: a review. Front. Mol. Neurosci. 7:21. doi: 10.3389/fnmol.2014.00021

Skiba, N. P., Spencer, W. J., Salinas, R. Y., Lieu, E. C., Thompson, J. W., and Arshavsky, V. Y. (2013). Proteomic identification of unique photoreceptor disc component reveals the presence of PRCD, a protein linked to retinal degeneration. J. Proteome Res. 12, 3010-3018. doi: 10.1021/pr4003678

Surguchov, A., Bronson, J. D., Banerjee, P., Knowles, J. A., Ruiz, C., Subbaraya, I., et al. (1997). The human GCAP1 and GCAP2 genes are arranged in a tail-to-tail array on the short arm of chromosome 6 (p21.1). Genomics 39, 312-322. doi: 10.1006/geno.1996.4513

Takemoto, N., Tachibanaki, S., and Kawamura, S. (2009). High cGMP synthetic activity in carp cones. Proc. Natl. Acad. Sci. U.S.A. 106, 11788-11793. doi: 10.1073/pnas.0812781106

Tsang, S. H., Woodruff, M. L., Chen, C.-K., Yamashita, C. Y., Cilluffo, M. C., Rao, A. L., et al. (2006). GAP-independent termination of photoreceptor light response by excess $\gamma$ subunit of the cGMP-phosphodiesterase. J. Neurosci. 26, 4472-4480. doi: 10.1523/JNEUROSCI.4775-05.2006 van Hateren, J. H., and Lamb, T. D. (2006). The photocurrent response of human cones is fast and monophasic. BMC Neurosci. 7:34. doi: 10.1186/1471-2202-7-34 Wensel, T. G. (2008). Signal transducing membrane complexes of photoreceptor outer segments. Vision Res. 48, 2052-2061. doi: 10.1016/j.visres.2008.03.010

Woodruff, M. L., Olshevskaya, E. V., Savchenko, A. B., Peshenko, I. V., Barrett, R., Bush, R. A., et al. (2007). Constitutive excitation by Gly90Asp rhodopsin rescues rods from degeneration caused by elevated production of cGMP in the dark. $J$. Neurosci. 27, 8805-8815. doi: 10.1523/JNEUROSCI.2751-07.2007

Woodruff, M. L., Sampath, A. P., Matthews, H. R., Krasnoperova, N. V., Lem, J., and Fain, G. L. (2002). Measurement of cytoplasmic calcium concentration in the rods of wild-type and transducin knock-out mice. J. Physiol. 542, 843-854. doi: 10.1113/jphysiol.2001.013987

Xu, J., Morris, L., Thapa, A., Ma, H., Michalakis, S., Biel, M., et al. (2013). cGMP accumulation causes photoreceptor degeneration in CNG channel deficiency: evidence of cGMP cytotoxicity independently of enhanced CNG channel function. J. Neurosci. 33, 14939-14948. doi: 10.1523/JNEUROSCI.0909-13.2013

Yang, R.-B., Robinson, S. W., Xiong, W.-H., Yau, K.-W., Birch, D. G., and Garbers, D. L. (1999). Disruption of a retinal guanylyl cyclase gene leads to cone-specific dystrophy and paradoxical rod behavior. J. Neurosci. 19, 58895897.

Zhang, X., Wensel, T. G., and Kraft, T. W. (2003). GTPase regulators and photoresponses in cones of the eastern chipmunk. J. Neurosci. 23, 1287-1297.

Conflict of Interest Statement: The authors declare that the research was conducted in the absence of any commercial or financial relationships that could be construed as a potential conflict of interest.

Received: 05 February 2014; accepted: 01 May 2014; published online: 02 June 2014. Citation: Wen X-H, Dizhoor AM and Makino CL (2014) Membrane guanylyl cyclase complexes shape the photoresponses of retinal rods and cones. Front. Mol. Neurosci. 7:45. doi: 10.3389/fnmol.2014.00045

This article was submitted to the journal Frontiers in Molecular Neuroscience.

Copyright (c) 2014 Wen, Dizhoor and Makino. This is an open-access article distributed under the terms of the Creative Commons Attribution License (CC BY). The use, distribution or reproduction in other forums is permitted, provided the original author(s) or licensor are credited and that the original publication in this journal is cited, in accordance with accepted academic practice. No use, distribution or reproduction is permitted which does not comply with these terms. 